\title{
$Q$-factor dependence of one-port encapsulated polysilicon resonator on reactive sealing pressure
}

\section{Chengqun Gui $\nmid$, Rob Legtenberg, Miko Elwenspoek and Jan H Fluitman}

MESE Research In'stitute, University of Twente, The Netherlands

Received 14 December 1994, accepted for publication 4 January 1995

Abstract. Micromachined encapsulated polysilicon resonators have been fabricated in different reactive sealing pressure, 200,50 and 20 mTorr, in order to investigate the dependence of the $Q$-factors on the sealing pressure. $Q$-factors as high as 2700 have been measured. The experimental results show that the $Q$-factors of one-port encapsulated resonators are proportional to $1 / p$ and the resonant frequency is independent of the sealing pressure. However, the measured $Q$-factors are more than two orders of magnitude lower than theoretical prediction.

\section{Introduction}

Vacuum encapsulated micromachined resonators are, very attractive for the precise measurement of quantities such as pressure, force and weight [1-8]. They offer high mechanical quality factors, high sensitivity and resolution, together with a semi-digital output. In 1988 Ikeda et al first fabricated single-crystalline silicon resonators housed in on-chip-vacuum shells, using a self-aligned selective epitaxial technology in combination with selective anisotropic etching and hydrogen evacuation techniques [1]. Another micro resonator has been presented by Guckel et al in 1990 [3,4]. They employed the polysilicon/silicon dioxide sacrificial layer etching technique to realize a similar structure. The most recent work in this area has been done by Tilmans et al in 1993 [5, 7,8]. They used the same fabrication process that Guckel et al developed but realized an electrostatically driven vacuum encapsulated doubly supported polysilicon resonator.

Reactive vacuum sealing of the sacrificial layer etching channels by LPCVD $\mathrm{Si}_{3} \mathrm{~N}_{4}$ is one of the most critical processes in fabricating encapsulated resonators, because the final cavity pressure and thus the $Q$-factors of the resonators are strongly dependent on the sealing process pressure. In the molecular regime, the mechanical quality factor $Q_{n}$ of micromachined resonators as a function of the ambient pressure $p$ can be expressed as $[5,9]$ :

$$
Q_{n}=\frac{3}{8 \sqrt{6}} \frac{\alpha_{n}^{2}}{p}\left(\frac{h}{l}\right)\left(\frac{\pi E \rho R T}{M}\right)^{1 / 2}
$$

$\dagger$ Tsinghua University, Beijing, China. where $\alpha_{n}$ is a constant depending on the boundary conditions and on the mode of vibration $n, h$ and $l$ are the thickness and the length of the resonator, $E$ and $\rho$ are Young's modulus and the density of the resonator beam, respectively, $R$ is the universal gas constant, $T$ is the absolute temperature and $M$ is the molecular mass of the gas in the cavity.

In this study, we experimentally investigated the quality factor dependence of the one-port electrostatically driven encapsulated polysilicon resonator on the reactive sealing pressure. The resonators have been sealed in three different process pressures, 200,50 and $20 \mathrm{~m}$ Torr. The experimental results are given.

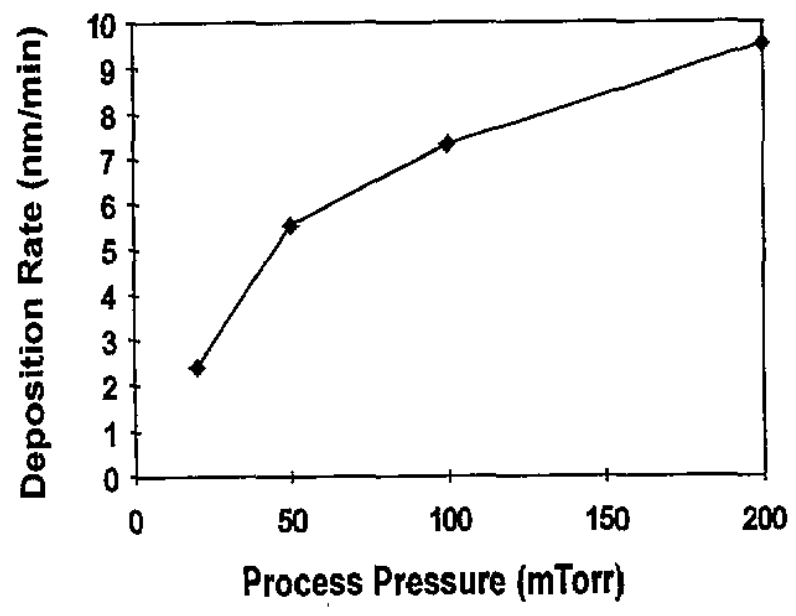

Figure 1. LPCVD $\mathrm{Si}_{3} \mathrm{~N}_{4}$ deposition rate as a function of process pressure $\left(T=850^{\circ} \mathrm{C}\right)$. 
Table 1. Parameters of $L P C V D \mathrm{Si}_{3} \mathrm{~N}_{4}$ reactive sealing process ${ }^{a}$.

\begin{tabular}{llllllllc}
\hline $\begin{array}{l}\text { Wafer } \\
\text { No }\end{array}$ & $\begin{array}{l}P_{\text {process }} \\
(\mathrm{mTorr})\end{array}$ & $\begin{array}{l}T_{\text {process }} \\
\left({ }^{\circ} \mathrm{C}\right)\end{array}$ & $\begin{array}{l}\mathrm{NH}_{3} \\
(\mathrm{sccm})\end{array}$ & $\begin{array}{l}\text { DCS } \\
(\mathrm{sccm})\end{array}$ & $\begin{array}{l}\text { Time } \\
(\mathrm{min})\end{array}$ & $\begin{array}{l}\text { Deposition } \\
\left(\mathrm{nm} \mathrm{min}^{-1}\right)\end{array}$ & $\begin{array}{l}\text { Thickness } \\
(\mathrm{nm})\end{array}$ & $\begin{array}{l}P_{\text {cavity }} \\
(\mathrm{mTorr})\end{array}$ \\
\hline 13 & 20 & 850 & 20 & 6.7 & 82 & 2.4 & 194 & 5.88 \\
14 & 50 & 850 & 66 & 22 & 36 & 5.5 & 205 & 14.70 \\
15 & 200 & 800 & 66 & 22 & 36 & 5.5 & 197 & 61.53 \\
\hline
\end{tabular}

a $\mathrm{DCS}=$ dichlorosilane, $\mathrm{SiCl}_{2} \mathrm{H}_{2} ; \operatorname{sccm}=$ standard cubic centimetres per minute.

\section{Experimental details}

The LPCVD $\mathrm{Si}_{3} \mathrm{~N}_{4}$ deposition rates in different process pressures have been determined experimentally (see figure 1). The overall chemical reaction for $\mathrm{LPCVD} \mathrm{Si}_{3} \mathrm{~N}_{4}$ reactive sealing process is [7]:

$$
3 \mathrm{SiCi}_{2} \mathrm{H}_{2}+10 \mathrm{NH}_{3} \rightarrow \mathrm{Si}_{3} \mathrm{~N}_{2} \downarrow+6 \mathrm{H}^{2} \uparrow+6 \mathrm{NH}_{4} \mathrm{Cl} \uparrow
$$

The final cavity pressure after sealing is a function of the processing pressure, temperature, the gas flows, the reaction products, subsequent diffusions and the change of the cavity volume before and after sealing [4]:

$$
P_{\text {cavity }}=P_{\text {process }} \frac{V_{\text {unsealed }}}{V_{\text {sealed }}} \frac{T_{0}}{T_{\text {process }}} \frac{n_{\text {right }}}{n_{\text {left }}}
$$

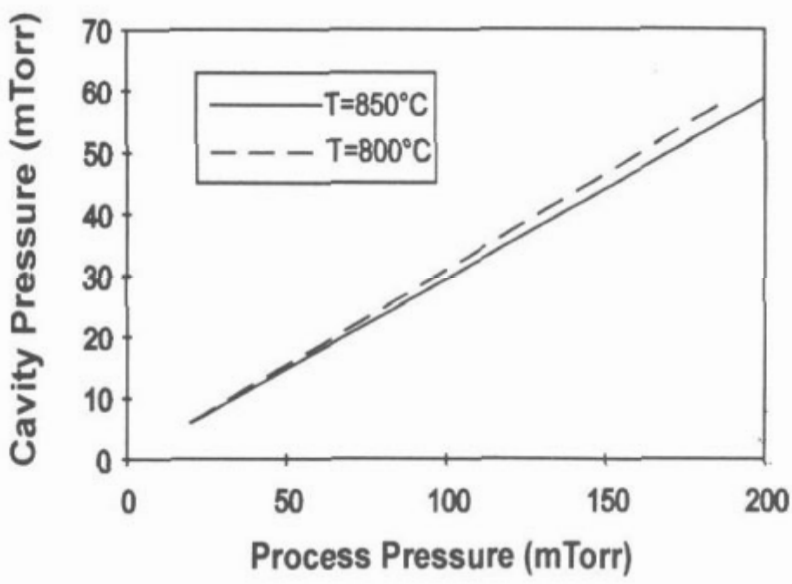

Figure 2. Dependence of final cavity pressure on sealing process pressure.

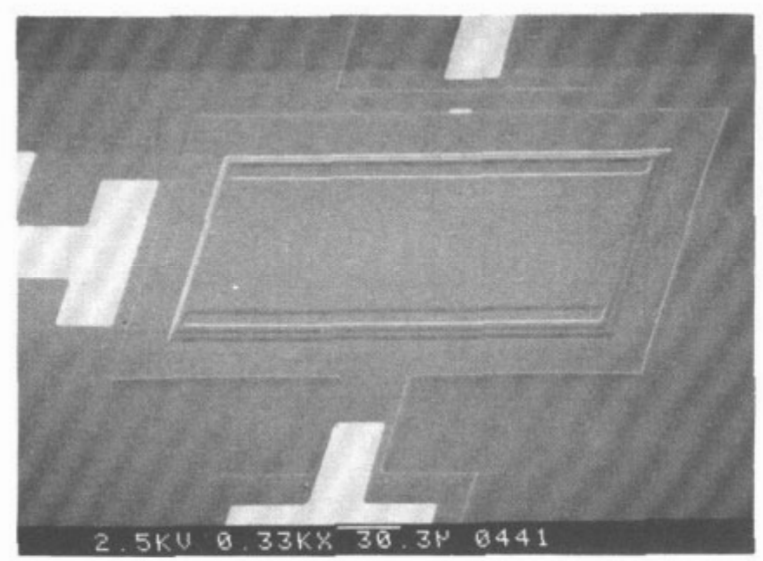

Figure 3. SEM photo of an encapsulated resonator.

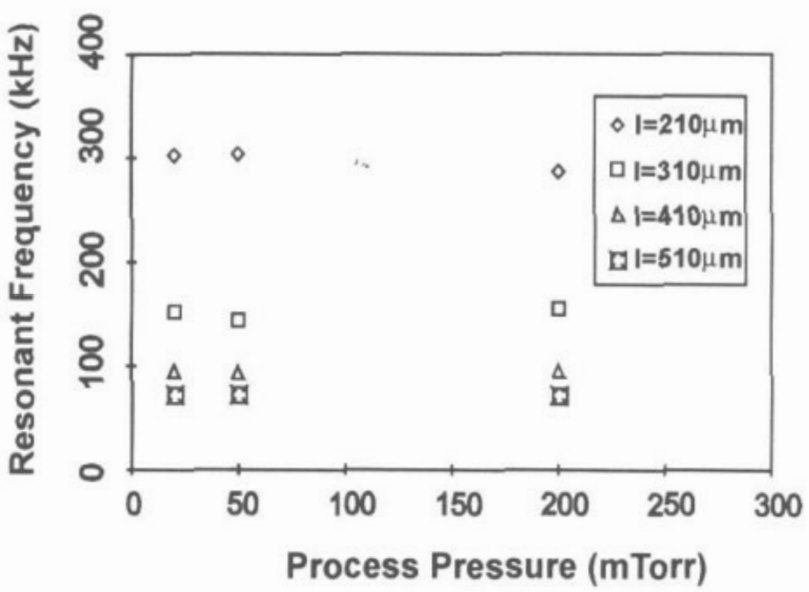

Figure 4. The first-order resonant frequency is independent of the reactive sealing pressure.

where $T_{0}$ and $T_{\text {process }}$ denote the room temperature and the process temperature respectively, $V_{\text {unsealed }}$ and $V_{\text {sealed }}$ represent the cavity volume before and after sealing, $P_{\text {process }}$ is the process pressure, and $n_{\text {right }} / n_{\text {left }}$ denotes the mole ratio of gaseous products and reactants.

The change of the volume of the cavity is mainly due to the deflection of the cap after sealing:

$$
\frac{V_{\text {unsealed }}}{V_{\text {sealed }}}=\frac{l_{\mathrm{c}} b_{\mathrm{c}}\left(h_{\mathrm{c} 1}+h_{\mathrm{c} 2}\right)}{l_{\mathrm{c}} b_{\mathrm{c}}\left(h_{\mathrm{c} 1}+h_{\mathrm{c} 2}-\delta h\right)}=\frac{h_{\mathrm{c} 1}+h_{\mathrm{c} 2}}{h_{\mathrm{c} 1}+h_{\mathrm{c} 2}-\delta h}
$$

where $l_{\mathrm{c}}$ and $b_{\mathrm{c}}$ denote the length and width of the cavity, respectively, $h_{\mathrm{cl}}$ and $h_{\mathrm{c} 2}$ denote the thickness and the first and the second sacrificial layer respectively, and $\delta h$ denotes the deflection of the cap after sealing. In our case an average deflection of $500 \mathrm{~nm}$ of the cap after sealing has been measured. For $h_{\mathrm{c} 1}=h_{\mathrm{c} 2}=1.5 \mu \mathrm{m}$, we obtain $V_{\text {unsealed }} / V_{\text {sealed }} \simeq 1.2$.

In equation (2), $n_{\text {right }} / n_{\text {left }}$ equals $12 / 13$. The dependence of final cavity pressure on the sealing process pressure at different process temperatures is shown in figure 2. The parameters of reactive sealing process are shown in table 1 .

\section{Results and discussion}

A SEM photo of the encapsulated polysilicon resonator is shown in figure 3 . The quality factors are extracted from the admittance plots, which are measured by using a HP4 149A impedance analyser.

For resonators sealed in $20 \mathrm{mTorr}, Q$-factors as high as 2700 have been measured. The measured mechanical 


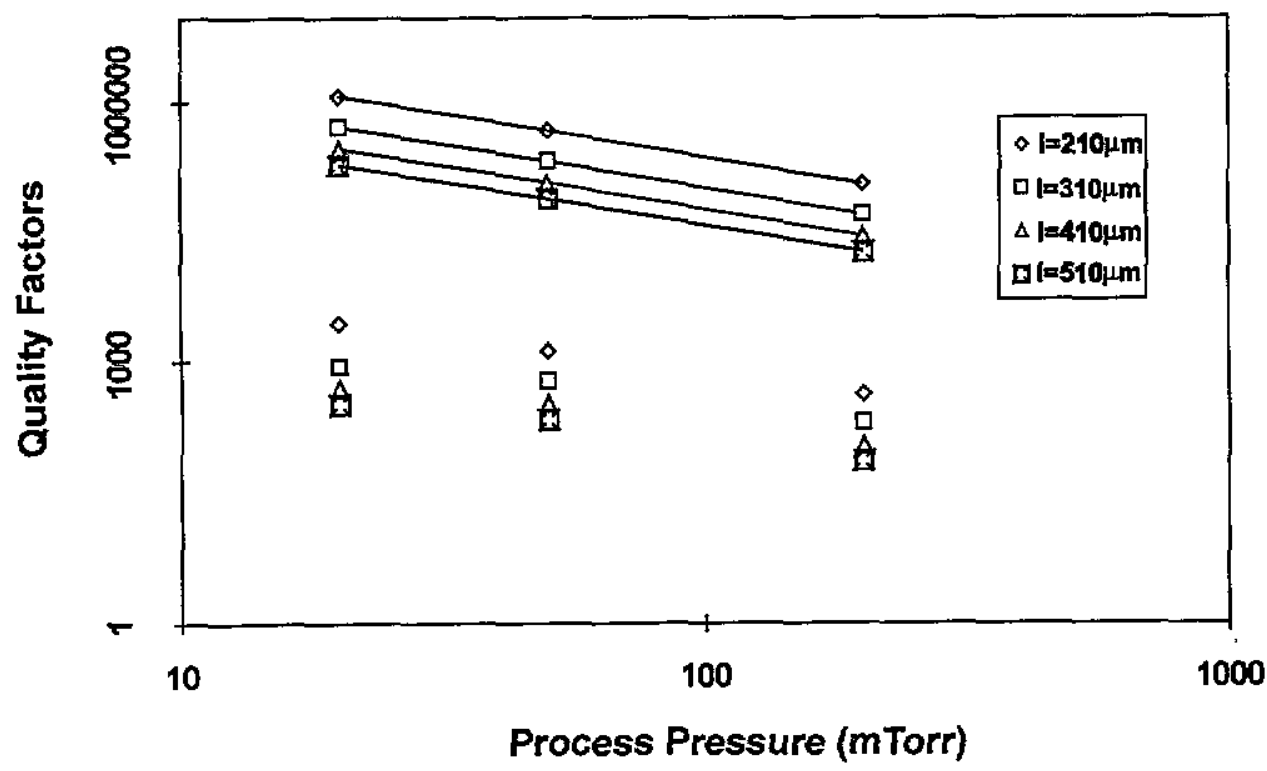

Figure 5. Q-factor dependence of one-port encapsulated resonators on the sealing pressure for all four beam lengths. The width and thickness of all four beams are $100 \mu \mathrm{m}$ and $1.5 \mu \mathrm{m}$. Symbols linked by lines are theoretical prediction, and those without lines are measured results.

quality factors for all four kinds of resonators are, as expected, proportional to $1 / p$. The measured first-order resonant frequency of all four kinds of resonators are independent of the sealing pressure (figure 4). These results show that the resonant beams are working in the molecular regime and that momentum damping is the dominant damping mechanism [5,9]. However the value of $Q$-factors are more than two orders of magnitude lower than theoretical prediction (figure 5). The reason for this discrepancy is under investigation. But we believe that it is most likely due to the fact that the assumption of free space surrounding the resonator is not true. In deriving the relationship between quality factors and surrounding pressures of micromachined beams, it was assumed that the surfaces except the one end support are very far away from the vibrating beam and will not influence the damping [9]. However, in encapsulated resonators, the beams are located in two narrow gaps. The ratio of the thickness of the gap and the width of the beam is $1 / 100$. In this case, the influence of the surfaces of the cap and the substrates on the damping should be taken into account.

\section{Acknowledgments}

The authors would like to thank Meint de Boer and Erwin Berenschot for their help in fabricating the encapsulated resonator samples. Bert Otter is acknowledge for making the SEM photographs. We thank Harries Tilmans very much for discussions.

\section{References}

[1] Ikeda K, Kuwayama H, Koyayashi T, Watanabe T, Nishikawa T and Yoshida T 1988 Silicon pressure sensor with resonant strain gauge built into diaphragm Proc. 7th Sensor Symp. (Tokyo, Japan) pp 55-8

[2] Putty M W, Chang S C, Howe R T, Robinson A L and Wise K D 1989 One-port active polysilicon resonant microstructures Proc. IEEE Micro Electro Mechanical System (Salt Lake City, Utah, February) pp 60-5

[3] Guckel H, Sniegowski J J, Christenson T R and Raiss F 1990 The application of fine-grained, tensile polysilicon to mechanically resonant transducers Sensors Actuators A 21-23 346-51

[4] Sniegowski J J, Guckel H and Christenson T R 1990 Performance characteristics of second generation polysilicon resonating beam force transducers $P$ roc. IEEE Solid-State Sensors and Actuators Workshop (Hilton Head Island, SC, June) pp 9-12

[5] Tilmans H A C 1993 Micro-mechanical sensors using encapsulated built-in resonant strain gauges $P h D$ Thesis University of Twente

[6] Elwenspoek M 1991 Micromechanical resonant sensors Journal A 15-21

[7] Tilmans H A C, Elwenspoek M and Fluitman J H J 1992 Micro resonant force gauges Sensors Actuators A 35-53

[8] Tilmans H A C, Legtenberg R, Schurer H; Ijntema D J, Elwenspoek M and Fluitman J H J 1993 (Electro-) mechanical characteristics of electrostatically driven vacuum encapsulated polysilicon resonators IEEE Trans. Ultrason. Ferroelectron. Freq. Control

[9] Blom F R, Bouwstra S, Elwenspoek $M$ and Fluitman $J$ H $J$ 1992 Dependence of the quality factor of micromachined silicon beam resonators on pressure and geometry J. Vac. Sci. Technol. B 19

[10] Duval P 1988 High Vacuum Production in the Microelectronics Industry (Amsterdam: Elsevier) p 17 